\title{
Diamond-Blackfan Syndrome. I. Erythropoiesis in Prednisone Responsive and Resistant Disease
}

\author{
HELEN S.L. CHAN, E. FRED SAUNDERS, AND MELVIN H. FREEDMAN ${ }^{(12)}$ \\ Division of Hematology, Hospital for Sick Children and Department of Pediatrics, University of Toronto, Toronto, \\ Ontario, Canada
}

\begin{abstract}
Summary
We studied the in vitro proliferative characteristics of marrow erythroid progenitors, colony forming unit-erythroid (CFU-E) and burst forming unit-erythroid (BFU-E), in two infants with Diamond-Blackfan syndrome before and during prednisone treatment. Patient 1 , had a brisk erythropoietic response to prednisone and the anemia improved; Patient 2 was steroid-unresponsive. Marrow from Patient 1 yielded linear increases in numbers of colonies in erythropoietin dose-response studies, and the magnitude of response was much greater while on prednisone compared to pretreatment. Cultures of stem cell rich fractions of marrow from Patient 1 separated by unit gravity sedimentation (STA-PUT) revealed moderately reduced CFU-E and BFU-E numbers before prednisone, but normal colony numbers during treatment. Patient 2 differed because CFU-E and BFU-E were almost absent at all erythropoietin doses before and during therapy. Even stem cell rich marrow fractions initially yielded very low colony numbers which did not increase significantly while on prednisone.

These findings suggest that in Patient 1 there were adequate numbers of progenitors that were able to differentiate normally only in the presence of prednisone. In Patient $\mathbf{2}$ the erythropoietic failure in vivo and in vitro was unaffected by prednisone.
\end{abstract}

\section{Speculation}

Diamond-Blackfan Syndrome is a heterogeneous disorder with at least two forms demonstrating different patterns of erythropoiesis. In one form erythroid precursors appear to be quantitatively normal but have a relative erythropoietin insensitivity which is correctable with prednisone. In the other form there is either a marked deficiency of numbers of progenitors or an absolute erythropoietin insensitivity.

Although the anemia in some patients with Diamond-Blackfan Syndrome (DBS) may be immune-mediated $(6,11)$, the evidence is convincing that most cases are due to an intrinsic defect of the erythroid stem cell $(2,3,10)$. The defect could be a decreased number of progenitors, a failure of the progenitors to respond to erythropoietin, or a combination of both mechanisms. The re- sponse to prednisone therapy in DBS is unpredictable. Some patients have a complete reversal of anemia whereas others show no response (1). This suggests that either the red cell aplasia has more than one pathogenesis or that a single defect exists with varying degrees of severity.

To clarify these possibilities, we studied the in vitro proliferative characteristics of marrow erythroid progenitors, colony forming unit-erythroid (CFU-E) and burst forming unit-erythroid (BFU$\mathrm{E}$ ), in two infants with DBS before and during prednisone treatment. The striking differences observed in their clinical responses to steroids and in their in vitro findings indicate that there are at least two mechanisms of red cell aplasia in this disorder.

\section{MATERIALS AND METHODS}

Subjects. The two infants with DBS fit the classic clinical and hematologic description (1). They presented with anemia in the newborn period and marrow aspirates from both showed normal cellularity with an isolated reduction in the red cell series in which erythroid elements never exceeded $0.5 \%$ of the differential count (Table 1). Both received red cell transfusions until 5 months of age at which time they were given a 4 wk course of prednisone, 2 $\mathrm{mg} / \mathrm{kg} /$ day. Patient 1 responded with a sharp increase in marrow erythropoiesis, a brisk reticulocytosis, a spontaneous rise in $\mathrm{Hb}$, and a loss of transfusion requirement (Table 1). As the prednisone dosage was tapered, the reticulocytosis disappeared and the hemoglobin decreased. Because of steroid toxicity the drug was discontinued after $8 \mathrm{wk}$ and transfusions reinstituted. One year later a second prednisone trial resulted in identical erythropoietic response with maintenance therapy requiring an unacceptable steroid dose.

Patient 2 failed to show any increase in erythropoiesis with 2 $\mathrm{mg} / \mathrm{kg}$ of prednisone and was considered to be steroid-unresponsive. The transfusion requirement persisted requiring $15 \mathrm{ml} / \mathrm{kg}$ of packed red cells every $4 \mathrm{wk}$. A second steroid trial at 12 months of age also failed.

Control bone marrow was obtained from three hematologically normal children from 1-7 years of age with localized solid tumor who had marrow aspirates performed as part of their medical investigation, and a healthy adult volunteer. This study was

Table 1. Hematologic data on two patients with Diamond-Blackfan Syndrome

\begin{tabular}{|c|c|c|c|c|c|c|}
\hline & \multicolumn{3}{|c|}{ Patient 1} & \multicolumn{3}{|c|}{ Patient 2} \\
\hline & $\begin{array}{c}\text { At } \\
\text { diagnosis }\end{array}$ & $\begin{array}{c}\text { Before }^{1} \\
\text { prednisone }\end{array}$ & $\begin{array}{c}\text { On } \\
\text { prednisone }\end{array}$ & $\begin{array}{c}\text { At } \\
\text { diagnosis }\end{array}$ & $\begin{array}{c}\text { Before }^{1} \\
\text { prednisone }\end{array}$ & $\begin{array}{c}\mathrm{On}^{1} \\
\text { prednisone }\end{array}$ \\
\hline $\mathrm{Hb}(\mathrm{g} / \mathrm{dl})$ & 1.9 & 8.2 & 8.5 & 2.1 & 7.0 & 7.4 \\
\hline Retic $(\%)$ & 0 & 0 & 10.0 & 0 & 0 & 0 \\
\hline WBC $\left(\times 10^{3} / \mathrm{mm}^{3}\right)$ & 6.5 & 8.4 & 9.9 & 15.9 & 9.0 & 7.0 \\
\hline Plat $\left(\times 10^{3} / \mathrm{mm}^{3}\right)$ & 350.0 & 280.0 & 350.0 & 684.0 & 580.0 & 680.0 \\
\hline Marrow erythroids (\%) & 0 & 0.5 & 40 & 0.5 & 0 & 0 \\
\hline
\end{tabular}

'Transfused. 
approved by the Human Experimentation Committee of the Hospital for Sick Children and informed consent obtained.

Marrow fractionation. Neutrophils and red cells were removed from heparinized marrow by centrifugation $(200 \times \mathrm{g}, 20 \mathrm{~min})$ over Ficoll-Paque (Pharmacia Fine Chemical, Upsala, Sweden). This cell suspension was either cultured directly for erythroid colonies or was further fractionated by unit gravity sedimentation in a STA-PUT $(5,8)$. Sedimentation was performed at $4^{\circ} \mathrm{C}$ for $3 \mathrm{~h}$ and $30 \mathrm{ml}$ fractions were collected. Pairs of adjacent fractions were pooled, the cells counted, and then cultured for erythroid colonies. Sedimentation velocities were calculated on a computer program (9).

Erythroid colony cultures ( $B F U-E$ and $C F U-E)$. Nucleated marrow cells were cultured in $0.8 \%$ methylcellulose, $30 \%$ fetal calf serum (Microbiological Associates, Bethesda, MD) and $1 \%$ bovine serum albumin (Sigma Chemical Co., St. Louis, MO) at a final volume of $1 \mathrm{ml} /$ culture plate (7). Human urinary erythropoietin (EPO) (National Heart Lung and Blood Institute, Bethesda, MD) of purity 3742 units/mg protein, was used in dose-response studies in concentrations of $0.1-5.0$ units $/ \mathrm{ml}$. A second preparation of purity 93.5 units/mg protein was used in STA-PUT experiments in a concentration of 1.0 units $/ \mathrm{ml}$. In all studies, $10^{5}$ marrow cells were plated per culture except in the EPO dose-response experiments in which $10^{6}$ DBS marrow cells were used. The cultures were incubated at $37^{\circ} \mathrm{C}$ in air with $5 \% \mathrm{CO}$. and high humidity. Cultures were harvested at 7 and 14 days and the colonies counted directly in the plates using an inverted microscope. An aggregate of more than 500 hemoglobinized cells or 3 or more erythroid subcolonies on day 14 was considered a "burst" or BFU-E colony (4). A CFU-E colony was defined as a cluster of 8 or more hemoglobinized cells on day 7. All studies were performed in duplicate and the results expressed as mean colony number $/ 10^{5}$ cells plated.

\section{RESULTS}

The EPO dose-responses for Patient 1 and a control are shown in Figures 1 and 2 for CFU-E and BFU-E, respectively. Before prednisone therapy was started, the marrow yielded linear increases in CFU-E and BFU-E in response to increasing doses of EPO, but the colony numbers were low. The maximum numbers of colonies seen with EPO 5 units/ml were 44 CFU-E and 10 BFU-E. During prednisone therapy, at the time of the clinical response, marrow from Patient 1 showed increases in colonies at all EPO doses with a maximum of $110 \mathrm{CFU}-\mathrm{E}$ and $22 \mathrm{BFU}-\mathrm{E} / 10^{5}$ at EPO 5 units $/ \mathrm{ml}$. At an EPO dose of 1 unit $/ \mathrm{ml}$, CFU-E and BFU-E were $62 / 10^{5}$ and $12 / 10^{5}$ respectively, both within control

CFU.E: $10^{5}$ CELLS

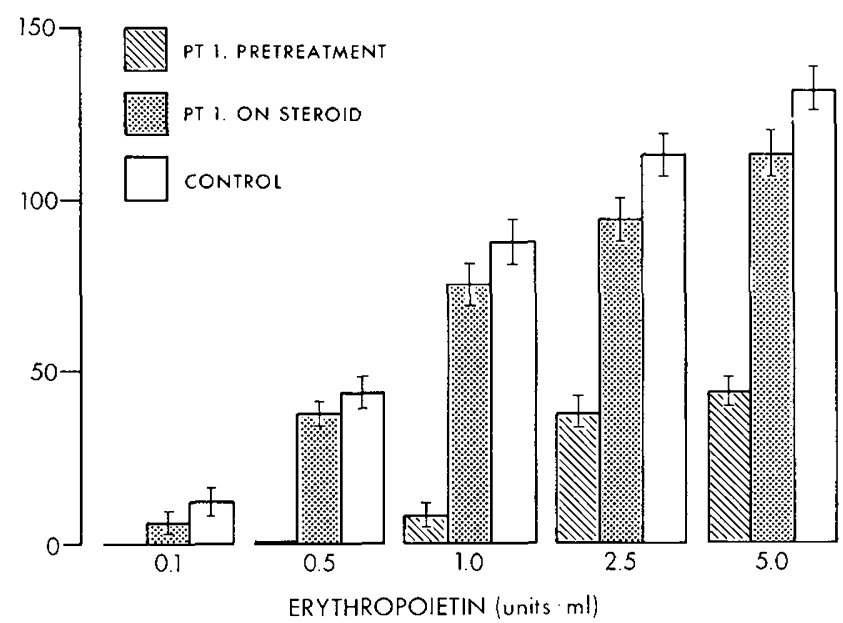

Fig. 1. Erythropoietin dose-response studies on marrow colony forming unit-erythroid (CFU-E) from Patient $I$ before and during prednisone therapy and a control.

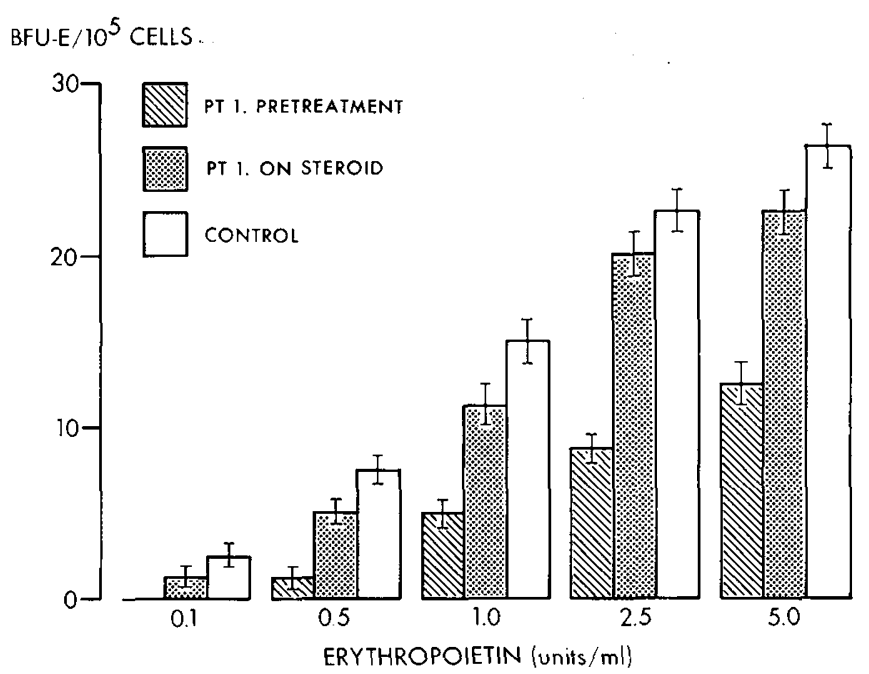

Fig. 2. Erythropoietin dose-response studies on marrow burst forming unit-erythroid (BFU-E) from Patient 1 before and during prednisone therapy and a control.

ranges established in our laboratory on studies of 69 children (mean \pm S.D., $93 \pm 33 \mathrm{CFU}-\mathrm{E} / 10^{\circ}$ and mean \pm S.D., $18 \pm 10$ BFU-E/ $\left.10^{5}\right)$.

The EPO dose-responses for Patient 2 differed from Patient 1. In the pretreatment study there was no increase in colonies with increasing EPO concentrations, and the marrow yielded a maximum of only 2 CFU-E $/ 10^{5}$ and 1 BFU-E/ $10^{5}$ with EPO 5 units/ $\mathrm{ml}$. After $4 \mathrm{wk}$ of prednisone, no erythropoietic response was seen clinically, and no increase in colonies was observed in culture. The studies were repeated $2 \mathrm{wk}$ later while still on prednisone and the results were reproducible.

The results of the STA-PUT experiments are shown in Figures 3 and 4 . In all the studies, the sedimentation velocity yielding maximum numbers of CFU-E was $7.9-8.1 \mathrm{~mm} / \mathrm{h}$ (mean \pm S.D., $8 \pm 0.1 \mathrm{~mm} / \mathrm{h})$ and of BFU-E $3.1-4.8 \mathrm{~mm} / \mathrm{h}(3.8 \pm 0.7 \mathrm{~mm} / \mathrm{h})$. Peak colonies from Patient 1 at diagnosis were $288 \mathrm{CFU}-\mathrm{E} / 10^{\circ}$ and $59 \mathrm{BFU}-\mathrm{E} / 10^{\circ}$. This value increased to $535 \mathrm{CFU}-\mathrm{E} / 10^{\circ}$ and $96 \mathrm{BFU}-\mathrm{E} / 10^{5}$ when on prednisone, similar to a control marrow with peaks of $519 \mathrm{CFU}-\mathrm{E} / 10^{5}$ and $76 \mathrm{BFU}-\mathrm{E} / 10^{5}$. Peak colonies from Patient 2 at diagnosis were only $45 \mathrm{CFU}-\mathrm{E} / 10^{5}$ and $8 \mathrm{BFU}$ $\mathrm{E} / 10^{5}$. At the end of the prednisone trial, there was only a slight increase to $73 \mathrm{CFU}-\mathrm{E}$ and $20 \mathrm{BFU}-\mathrm{E} / 10^{5}$, far short of the control colony numbers.

\section{DISCUSSION}

The major hallmark of the Diamond-Blackfan Syndrome is the marked reduction or absence of recognizable marrow erythroid elements in the presence of increased EPO levels (1). Although patients have similar hematologic features, DBS is obviously a heterogeneous disease. Patients vary widely in their response to prednisone, some developing erythropoiesis with less than physiologic doses, others requiring $2 \mathrm{mg} / \mathrm{kg} /$ day, yet others failing to respond. Diamond and co-workers (1) have reported spontaneous remissions after years of transfusion, as well as continuation of remission after stopping prednisone. This variability suggests the presence of more than one pathogenesis for this condition.

The availability of tissue culture assays for hematopoietic progenitors has provided an opportunity to examine the proliferative characteristics of erythroid precursors that lack recognizable markers. Most workers agree that when DBS marrows are cultured in the conventional way, both CFU-E and BFU-E are reduced in number $(2,3,10)$. However, by plating increased concentrations of marrow cells we have been able to obtain moderate numbers of CFU-E and BFU-E from some untreated patients allowing study of erythropoiesis in vitro. 


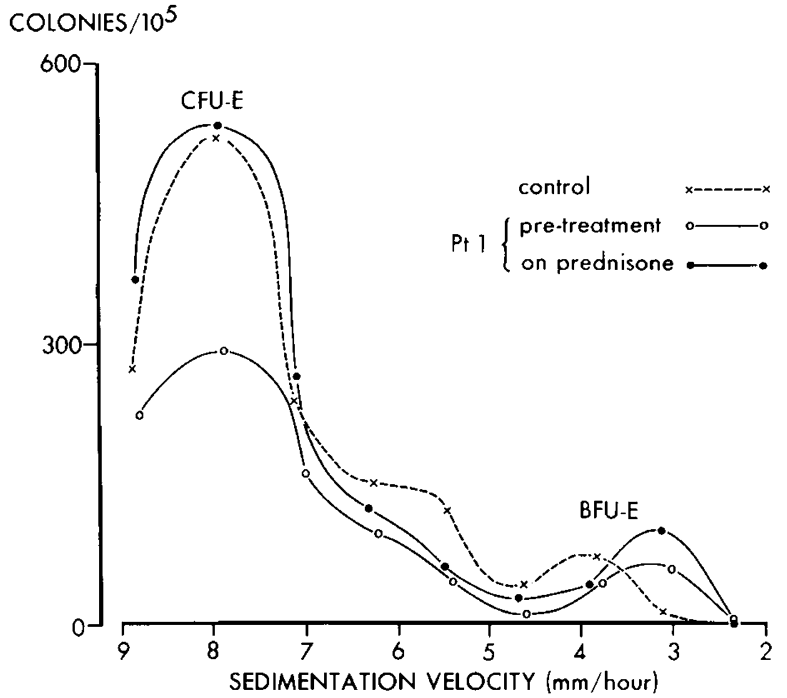

Fig. 3. Unit gravity sedimentation cell fractionation profiles for marrow colony forming unit-erythroid (CFU-E) and burst forming unit-erythroid (BFU-E) from Patient 1 before and during prednisone therapy, and from a control. Erythropoietin 1 unit $/ \mathrm{ml}$ and $10^{5}$ nucleated cells were used in the cultures of each fraction.

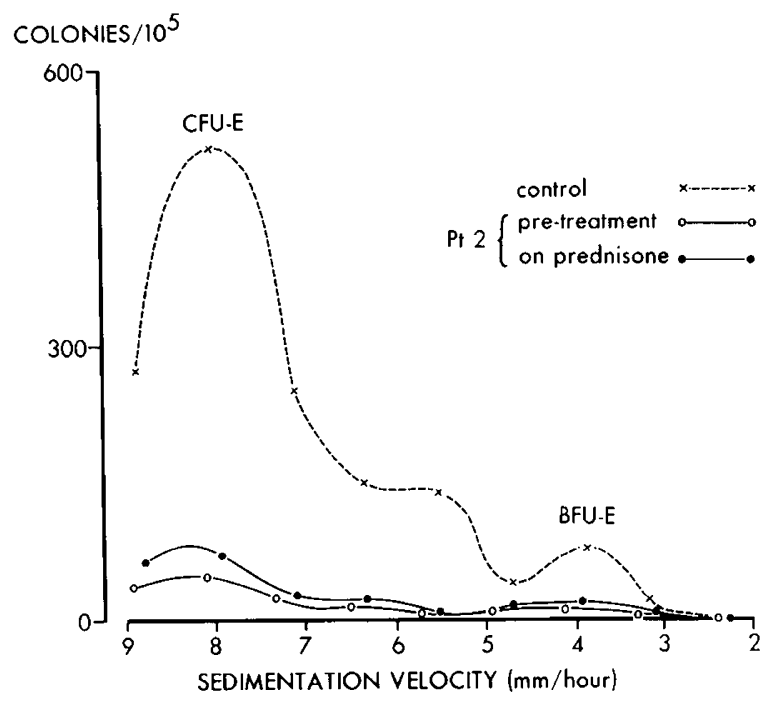

Fig. 4. Unit gravity sedimentation cell fractionation profiles for marrow colony forming unit-erythroid (CFU-E) and burst forming unit-erythroid (BFU-E) from Patient 2 before and during prednisone therapy and from a control. Erythropoietin 1 unit/ml and $10^{3}$ nucleated cells were used in the cultures of each fraction.

Our studies illustrate differences among DBS patients. Both infants had identical clinical and hematologic presentations, yet Patient 1 had a beneficial effect from prednisone, and Patient 2 was steroid resistant. As well, there were striking differences in the marrow culture findings. Patient 1 had moderate CFU-E and BFU-E numbers at diagnosis which showed an EPO dose response. Patient 2 had almost no colony growth which failed to increase with high EPO concentrations. With prednisone therapy, colony numbers increased to normal numbers in Patient 1 , whereas no increase was seen in Patient 2, corresponding to the clinical situation.
Colony counts from marrow cultures measure the concentration but not the absolute number of progenitor cells. Because the proportions of the various cells plated are changed in abnormal bone marrows, comparison with controls and interpretation of results are difficult. We tried to overcome this problem by fractionating marrow according to cell size, thus obtaining more homogeneous cell populations for culture and allowing comparisons to controls and between patients.

The STA-PUT data from Patient 1 indicate moderate proliferative activity of erythroid progenitors at diagnosis, even though the marrow was almost devoid of recognizable erythroid cells. The BFU-E number was not much lower than control. This finding differs from that of Nathan et al. (10) who found markedly reduced or absent BFU-E in DBS. The effect of prednisone therapy was very dramatic; CFU-E and BFU-E numbers increased to control values. These findings suggest that in Patient 1 , there were normal numbers of progenitors that were unable to differentiate in vivo. An end-organ resistance to EPO would explain the data. Prednisone improves such a defect and allows progenitor replication, possibly by action at the cell receptor level. In contrast, the STA-PUT data from Patient 2 showed almost no detectable erythroid precursors at diagnosis. There was no significant change after a therapeutic trial of prednisone. There are two possible interpretations of these data. Either there was a quantitative deficiency of progenitors as may be seen in a true "aplasia" or the progenitors were present as in Patient 1; however, the defect was almost completely resistant to EPO, which was unchanged by prednisone. Current technology cannot distinguish between these two possibilities.

From our study, we conclude that the Diamond-Blackfan Syndrome is a heterogeneous disorder. There seems to be at least two forms of the condition judging from the in vitro findings in our patients.

\section{REFERENCES AND NOTES}

1. Diamond, L. K., Wang. W. C., and Alter, B. P.: Congenital hypoplastic anemia Adv. Pediatr., 22: 349 (1976).

2. Freedman. M. H., Amato, D., and Saunders, E. F.: Erythroid colony growth in congenital hypoplastic anemia. J. Clin. Invest., 57: 673 (1976).

3. Freedman, M. H. and Saunders, E. F.: Diamond-Blackfan Syndrome. Evidence against cell-mediated erythropoietic suppression. Blood, 51: 1125 (1978).

4. Gregory, C. J. and Eaves, A. C.: Human marrow cells capable of erythropoietic differentiation in vitro: Definition of three erythroid colony responses. Blood. 49: 855 (1977).

5. Heath, D. S., Axelrad, A. A., McLeod, D. L., and Shreeve, M. M.: Separation of erythropoietin-responsive progenitors BFU-E and CFU-E in mouse bone marrow by unit gravity sedimentation. Blood, 47: 777 (1976).

6. Hoffman, R., Zanjani, E. D., Vila. J., Zalusky, R., Lutton, J. D., and Wasserman, L. R.: Diamond-Blackfan syndrome: lymphocyte-mediated suppression of erythropoiesis. Science, 193: 899 (1976).

7. Iscove, N. N., Sieber, F.. and Winterhalter, K. H.: Erythroid colony formation in cultures of mouse and human marrow: Analysis of the requirement for erythropoietin by gel filtration and affinity chromatography on agarose-concanavalin A. J. Cell. Physiol., 83: 309 (1974).

8. Miller, R. G. and Phillips, R. A.: Separation of cells by velocity sedimentation J. Cell. Physiol.. 73: 191 (1969).

9. Moon. R., Phillips, R. A.. and Miller, R. G.: Sedimentation and volume analysis of human bone marrow. Ser. Haematol. 5: 163 (1972).

10. Nathan, D. G., Clarke. B. J.. Hillman, D. G., Alter, B. P., and Housman, D. E. Erythroid precursors in congenital hypoplastic (Diamond-Blackfan) anemia. J. Clin. Invest., 61: 489 (1978).

11. Steinberg, M. H., Coleman, M. F., and Pennebaker, J. B.: Diamond-Blackfan syndrome: evidence for T-cell mediated suppression of erythroid development and a serum blocking factor associated with remission. Brit. J. Haematol., 4l: 57 (1979)

12. Requests for reprints should be addressed to: M.H. Freedman, M.D., Division of Hematology. Hospital for Sick Children, 555 University Ave., Toronto, Ontario, Canada. M5G 1 X8.

13. Supported by Medical Research Council of Canada Grant MA-4982 and by Physicians Services Incorporated Foundation.

14. Received for publication June 11, 1981.

15. Accepted for publication November 10, 1981. 